\title{
Building The Renewable Independent Energy Village by Using Portable Digester Technology in Facing the 4.0 Industrial Era (GenBIoT)
}

\author{
Rais $^{1}$, Arfan Haqiqi ${ }^{2}$, Eko Budihartono ${ }^{3}$, Rivaldo Mersis Brilianto ${ }^{4}$ \\ ${ }^{1}$ Program Studi DIII Teknik Komputer, Politeknik Harapan bersama \\ Jl. Mataram No. 09, Pesurungan Lor, Kec. Margadana, Kota Tegal, Indonesia 52142 \\ e-mail : rais.hojawa@gmail.com \\ ${ }^{2}$ Program Studi DIII Teknik Komputer, Politeknik Harapan bersama \\ J1. Mataram No. 09, Pesurungan Lor, Kec. Margadana, Kota Tegal, Indonesia 52142 \\ e-mail : Arfan.hqq@gmail.com \\ ${ }^{3}$ Program Studi DIII Teknik Komputer, Politeknik Harapan bersama \\ Jl. Mataram No. 09, Pesurungan Lor, Kec. Margadana, Kota Tegal, Indonesia 52142 \\ e-mail : tara.niscita@gmail.com \\ ${ }^{4}$ Program Studi DIII Teknik Komputer, Politeknik Harapan bersama \\ Jl. Mataram No. 09, Pesurungan Lor, Kec. Margadana, Kota Tegal, Indonesia 52142 \\ e-mail : Rivaldomersisb@gmail.com
}

\section{ARTICLE INFO}

Article history:

Received 30 September 2020

Received in revised form 2 Oktober 2020

Accepted 10 Oktober 2020

Available online 22 Oktober 2020

\begin{abstract}
The waste processing and renewable energy are being the issues in the industrial 4.0 era. Kitchen and organic trash in the rural areas will become a disaster if there is no solutions. On the other hand, kitchen and organic waste have a positive side, that they can be converted into biogas which can be converted into electricity. On the Minister of Energy and Mineral Resources Regulation Number 27 of 2014, supports the development of biogas and will buy electricity from the biogas conversion. The potential for biogas that obtained by the organic trash per 1000 people is 7619.8 liters of biogas, it meas that the energy contained is still abundant and the production can still be increased if processed with a modern digester system. This research produces a tool in the form of a portable digester that named GenBIoT (IoT-based Biogas Generator) which can be used by the public to produce biogas that used by home industries or general factories. This research used the research method that similar to System Development Life Cycle (SDLC), this tool is built with several stages starting from planning analysis, designing, functional testing, data analysis and reporting of the results or implementing this tool that can be used as an alternative, as a cheap and easy source energy. This tool is based on the Internet of Things so that this tool can be monitored regarding gas pressure in the reactor, biogas volume and it will detect if there is a biogas leak so it will displayed on the system. To produce the maximum biogas composition, $50 \%$ of cow dung
\end{abstract}


p-ISSN: 1907-0012 e-ISSN : 2714-5417

is required, $40 \%$ of kitchen trash and $10 \%$ of water production with energy produced from biogas per with a ratio of 5: 4: 1 so it will produce $40 \mathrm{~kg}$ of day of $716.39 \mathrm{Wh}$

biogas with a volume of methane gas (VGM) 0.11

$\mathrm{m} 3$ of biogas for cow dung. and $0.04 \mathrm{~m} 3$. The third Keywords: GenBIoT, Biogas, Energy

experiment becomes the basis of future biogas

\begin{abstract}
Abstrak
Pengolahan sampah dan energi terbarukan menjadi isu dalam era industri 4.0. Limbah dapur dan sampah organik di pedesaan akan menjadi masalah serius jika tidak dicari penyelesaianya. Disatu sisi limbah dapur dan sampah organik memiliki dampak positif yaitu dapat di ubah menjadi biogas yang nantinya dapat dikonversi menjadi listrik ataupun untuk kebutuhan dapur. Peraturan Menteri ESDM Nomor 27 Tahun 2014, mendukung pengembangan biogas dan akan membeli listrik dari hasil konversi biogas. Potensi biogas dari sampah organik per 1000 orang adalah 7619,8 liter biogas, artinya energi yang terkandung masih sangat melimpah dan produksinya masih bisa ditingkatkan jika diolah dengan sistem digester yang modern. Penelitian ini menghasilkan alat berupa Digester portable atau nama lainya adalah GenBIoT (Generator Biogas berbasis IoT) dapat dimanfaatkan oleh masyarakat secara umum untuk menghasilkan biogas yang dapat dimanfaatkan oleh industri rumahan atau pabrik secara umum. Dengan menggunakan metode penelitian yang hampir mirip seperti System Development Life Cycle (SDLC) maka alat ini dibangun dengan beberapat tahapan mulai dari analisis perencanaan, perancangan, uji fungsional, analisis data dan pelaporan hasil atau implementasi alat ini dapat dijadikan aternatif sebagai sumber energai murah dan mudah. Alat ini berbasis Internet of Things sehingga alat ini dapat dimonitoring terkait tekanan gas pada reaktor, volume biogas serta jika ada kebocoran biogas maka disiste akan kelihatan. Untuk mengahasilkan biogas yang maksimal dibutuhkan komposisi kotoran sapi sebesar $50 \%$, sampah dapur sebesar $40 \%$ dan air sebesar 10\% dengan perbandingan 5:4:1 akan menghasilkan $40 \mathrm{~kg}$ biogas dengan volum gas metana (VGM) biogas $0,11 \mathrm{~m} 3$ untuk kotoran sapi dan $0,04 \mathrm{~m} 3$. Percobaan ketiga menjadi landasan untuk produksi biogas masa mendatang dengan energi yang dihasilkan dari biogas per hari sebesar 716,39 Wh
\end{abstract}

Kata Kunci : GenBIoT, Biogas, Energi

\title{
1. PENDAHULUAN
}

Negara Indonesia segera menginjak tahun 2020, dimana saat ini dunia sedang bergiat memasuki era industri 4.0. Hampir semua bidang yang berhubungan dengan elektronik, mesin dan internet bisa saling terintegrasi dan bersinergi untuk menyelesaikan suatu tugas tertentu, inilah yang disebut jaman serba "Internet of Things (IoT)". Berbagai bidang seperti bidang pangan, tekstil, otomotif, elektronik, dan kimia menjadi fokus utama implementasi industri 4.0 di Indonesia. Ke depan, jika bidang-bidang tersebut berhasil dikembangkan, maka tingkat kesejahteraan bangsa bisa meningkat karena semua proses pengerjaan bisa dipercepat, transparan, dan memiliki tingkat akurasi yang tinggi. Namun perlu adanya perhatian lebih terhadap dampak negatif yang ditimbulkan, serta jawaban atas kebutuhan energi yang diperlukan guna menopang pengembangan pada sektor-sektor tersebut. Bidang makanan dan minuman yang dikonsumi masyarakat sudah pasti ikut berperan besar dalam menyumbang 64 juta ton sampah pertahun secara nasional, baik itu sampah organik sebesar $60 \%$ dan sisanya berupa sampah anorganik [1]. Tidak berhenti disitu saja, sebanyak $24 \%$ sampah tidak dikelola dengan baik, yang artinya ada sekitar 1,3 juta ton sampah plastik yang makin menambah beban lingkungan [2]. Kemudian bidang-bidang lainnya pasti membutuhkan energi dalam jumlah yang tidak sedikit untuk beroprasi dan berkembang. Berdasarkan keputusan Menteri ESDM Nomor 143K/20/MEM/2019 tentang Rencana Umum Ketenagalistrikan Nasional Tahun 20192038, memproyeksikan rata-rata pertumbuhan kebutuhan energi listrik nasional sekitar 6,9 persen per tahun dimana konsumsi paling banyak nantinya berasal dari sektor industri disusul oleh sektor rumah tangga, bisnis, publik. Sedangkan data dari Rencana Umum Penyediaan Tenaga Listrik (RUPTL) Perusahaan Listrik Negara (PLN) tahun 2010-2019 menyebutkan bahwa kebutuhan tenaga listrik diperkirakan mencapai 55.000 MW dan dari total daya tersebut, hanya sebanyak $32.000 \mathrm{MW}$ (57 persen)yang akan dibangun oleh PLN [3]. Ini berarti akan selalu ada defisit energi per periode pembangungan pembangkit listrik di Indonesia. Jadi dua masalah besar, yaitu sampah dan khususnya energi terbarukan patut segera dipecahkan supaya indonesia mampu menciptakan kemandirian energy. 
Dalam penelitian ini, solusi pengelolaan sampah dan energi terbarukan akan diangkat dari tingkat pedesaan terlebih dahulu. Regenerasi menjadi salah satu kunci utama dalam membangun masyarakat, mengingat pada 2030 Indonesia akan menyambut bonus demografi. Urbanisasi menjadi penopang jalannya kota, maka dari itu jika masyarakat pedesaan dipupuk untuk mengolah sampah, maka generasi mendatang akan belajar mengelola sampah saat mereka pindah di perkotaan. Sehingga secara otomatis, kota juga akan bersih karena masyarakatnya sudah terdidik. Di tingkat desa, lahan untuk mengelola sampah juga masih luas, namun hanya terbatas pada kelangkaan energi. Menimbang lebih lanjut, jumlah keluarga di desa xxxx adalah 1000 orang. Jika kita menghitung berdasarkan data dari Pengelolaan Limbah, Sampah, dan Bahan Beracun Berbahaya (PSLB3) KLHK, rata-rata setiap orang membuang sampah sebesar 0,7 kg/hari maka ada sekitar $700 \mathrm{~kg}$ sampah, yang mana $50 \%$ nya berupa sampah organik (dapur dan dedaunan)[4]. Jadi ada $350 \mathrm{~kg}$ atau 1,652 liter sampah organik di desa tersebut, justru ini adalah angin segar karena ada sumber energi terbarukan setiap harinya bagi sebuah desa. Sampah organik dapat diubah menjadi biogas sehingga nantinya dapat digunakan untuk menghidupkan kompor ataupun energi listrik [5]. Rata-rata setiap 1 liter limbah rumah tangga menghasilkan 4,61 liter biogas, sehingga ada 7619,8 liter biogas tersedia pada akhir periode fermentasi biodigester. Pemerintah mendorong pengembangan biomassa dan biogas dengan terbitnya Peraturan Menteri ESDM Nomor 27 Tahun 2014 tentang Pembelian Tenaga Listrik dari Pembangkit Listrik Tenaga Biomassa dan Pembangkit Listrik Tenaga Biogas oleh PT Perusahaan Listrik Negara (Persero). Jika setiap desa mampu membangun pembangkit listrik secara mandiri untuk selanjutnya digunakan ataupun dijual ke PLN maka nantinya akan ada surplus listrik setiap tahun. Dari sinilah ide penelitian ini dibuat.

Sampai saat ini banyak ditemui di masyarakat desain biogas pendam, yaitu biogas yang dipendam di dalam tanah. Rancangan ini menyulitkan pemeliharaan dan pengecekan kebocoran sistem digester. Selain itu, biaya pembuatan dan perancangan sebuah digester pendam ukuran $4 \mathrm{~m}^{3}$ sekitar 10-12 juta rupiah dan belum termasuk biaya pelatihan serta biaya tukang. Dalam penelitian ini, kami mengajukan desain digester portabel yang memungkinkan digester bisa dibawa dan mudah dipasang. Dengan demikian, desain biogas portabel bisa dibuat di pabrik untuk dikirim dan diterapkan di lapangan. Selain itu digester rancangan kami sudah dipadukan dengan teknologi IoT yang akan memudahkan operator pemerintah dalam monitoring biogas dan juga memetakan sebaran digester portabel di suatu daerah. Dengan demikian, pemerintah akan dapat melihat potensi secara lebih transparan dan dapat berusaha untuk meningkatkan produksi biogas untuk selanjutnya membangun pembangkit listrik skala mikro tenaga biogas di daerah tersebut.

\section{TINJAUAN PUSTAKA}

Penelitian yang dilakukan oleh Marsudi (2012) dengan judul Produksi Biogas Dari Limbah Rumah Tangga Sebagai Upaya Mengatasi Krisis Energi Dan Pencemaran Lingkungan dalam penelitan ini dijelaskan bahwa penelitian Limbah rumah tangga merupakan komponen yang cukup berbahaya jika dibuang begitu saja karena akan menimbulkan bau busuk, penyakit dan mencemari air terutama air tanah yang banyak dipakai sebagai air minum. Sehingga limbah rumah tangga perlu diolah agar menjadi energi yang bermanfaat. Metode penelitian yang digunakan dengan tahapan pembuatan alat reaktor dan pengujian dengan memasukkan limbah rumah tangga yang dicampur kotoran ternak dan air ke dalam reaktor lalu mencatat hasilnya kemudian menguji biogasnya. Reaktor biogas dengan volume 120 liter terdiri dari tampungan utama limbah dan tampungan biogas. Proses fermentasi berlangsung selama 50 hari dengan hasil-hasil sebagai berikut dari 100 liter limbah rumah tangga, kotoran ternak dan air yang diproses fermentasi maka didapat biogas sejumlah 0,55432 $\mathrm{m} 3$ atau 554,32 liter biogas. Dengan tekanan tertinggi $106,5 \mathrm{kN} / \mathrm{m} 2$. Temperatur yang terjadi di dalam reaktor 29 - 31 sesuai dengan batas aman yang diisaratkan untuk permentasi yaitu 25 - 40 [6].

Penelitian lain yang dilakukan oleh Andreas Felix S, dkk (2012) pada penelitiannya yang berjudul Pembuatan Biogas dari sampah sayuran. Tujuan dari penelitian ini adalah untuk membuat biogas dari sampah sayuran yang berasal dari pasar tradisional secara batch, mengetahui konsentrasi dan komposisi sampah sayuran dalam slurry dengan air dan ditambah kotoran sapi, serta mengetahui nilai kalor dan kapasitas produksi biogas yang terbentuk. Alat yang digunakan adalah jerigen plastik dan biodigester floating drum sederhana yang dilengkapi manometer dan dioperasikan pada suhu kamar, tekanan atmosferik. Variabel berubah yang dilakukan antara lain konsentrasi slurry $6-10 \%$ (berat kering/volume) serta komposisi $1: 0,1: 0,5$ dan $1: 1$ perbandingan berat sampah sayuran dengan kotoran sapi. Volume akumulasi tertinggi biogas dicapai pada konsentrasi $9 \%$ dengan komposisi $1: 0,5$. Berdasarkan hasil uji volume, dilakukan uji bakar dengan konsentrasi dan komposisi terbaik untuk mengetahui nilai kalornya. Nilai kalor biogas tertinggi yakni 10081 Joule/hari [5].

Selain itu pada penelitian yang dilakukan oleh Guyup Mahardhian Dwi Putra, dkk (2017) dengan judul penelitian rancang bangun reaktor biogas tipe portable dari limbah kotoran ternak sapi. Dalam penelitian ini

JURNAL ILMIAH ELEKTRONIKA DAN KOMPUTER, Vol.14, No.1, Juli 2021, pp. 26-34 
p-ISSN: 1907-0012 e-ISSN : 2714-5417

dijelaskan bahwa metode yang digunakan pada penelitian ini adalah metode eksperimental dengan mengukur parameter suhu reaktor biogas, tekanan, derajat keasaman $(\mathrm{pH})$ dan volume gas yang dihasilkan. Penelitian ini menggunakan bahan kotoran sapi dan air dengan perbandingan 1:2 pada kapasitas 200 liter. Pengambilan data dilakukan selama 37 hari. Hasil dari penelitian ini adalah sebuah alat biodigester skala laboratorium tipe floating drum atau terapung yang terbuat dari bahan plastik dan fiber glass dengan diamater reaktor $52 \mathrm{~cm}$ dan tinggi $92 \mathrm{~cm}$. Volume biogas yang dihasilkan selama 37 hari adalah 2,721 $\mathrm{m} 3$ dengan ata-rata pembentukan gas sebesar 0,074 m3/hari dan laju pembakaran 66,44 liter/jam [7].

Dari beberapa penelitian sebelumnya bahwa kotoran sapi dan sampah organik yang paling banyak digunakan dalam pembuatan reaktor digester dengan lama waktu yang dibutuhkan untuk menghasilkan gas metana stabil sekitar 22-30 hari.

\section{METODOLOGI PENELITIAN}

\subsection{Bahan dan Alat Penelitian}

Bahan penelitian :

1. kotoran sapi yang sudah dibersihkan dari rumput ataupun batu.

2. Sampah organik yang sudah dibersihkan.

Alat penelitian diantaranya :

a. Tang air $250 \mathrm{~L}$

b. Timbangan analitis

c. Sensor Ultrasonik

d. Raspberry pi

e. Pipva 0,5 inc

f. Humidity Sensor DHT12

\subsection{Alur Penelitian}

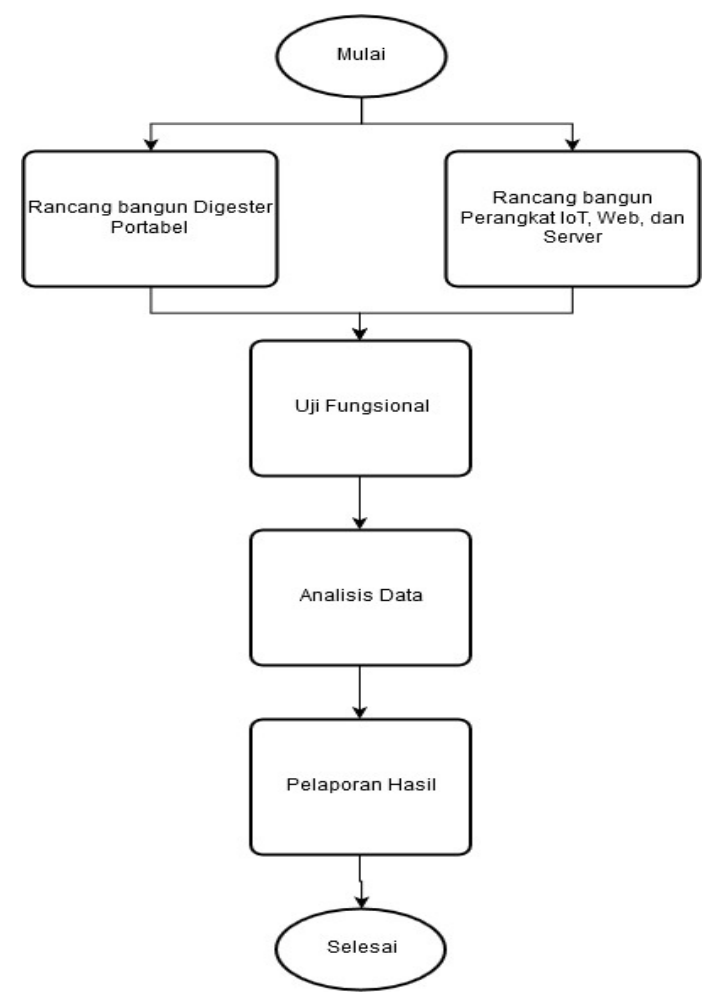

Gambar 1. Alur Penelitian

1. Rancang bangun digester portable

Perancangan desain kerangka Genbiot dengan bantuan software CAD. Desain kerangka GenBiot 3D dipilih, lalu dilakukan penyesuaian komponen mesin dan komponen elektronika di dalam desain kerangka 3D. 
2. Rancang bangun IoT

Pembuatan website genbiot yang digunakan untuk memonitoring berbagai macam parameter (tekanan gas reaktor, volum reaktor, suhu reaktor, dan volum kolektor). Didalam website juga terdapat tampilan grafik dan data juga dapat di ekspor menjadi file excel.

3. Uji fungsional

Sebelum melakukan uji fungsional, terlebih dahulu dilakukan pengecekan sambungan pipa ,perkabelan, dan uji sensor. Pengujian biogas diuji dengan mengganti isi slurry sesuai table pengujian 1.1 .

4. Analisis Data

Data hasil pengujian kemudian dianalisis dengan membandingkan volum gas yang terdapat di kolektor bergantung pada jenis slury pada table pengujian.

5. Pelaporan Hasil

Pelaporan hasil dapat dilihat pada sisem monitoring dalam bentuk interface berbentuk website.

\subsection{Rancangan Digester Portable}

Desain digester ini memiliki kelebihan berupa ringkas serta sudah mendukung teknologi IoT untuk keperluan monitoring, pada digester tersebut terdapat tiga tangki utama yaitu tangki digester, tangki pemurni biogas, tangki penyimpan biogas. Tangki digester (berwarna merah padam) berfungsi sebagai input, proses fermentasi biogas, dan sekaligus output berupa pupuk cair organik

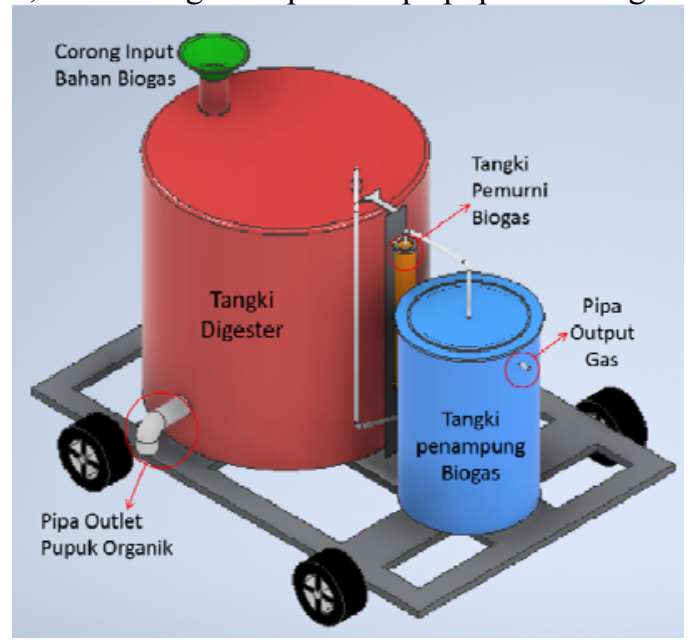

Gambar 2. Desain Digester Portable

\subsubsection{Volume biogas $(\mathrm{m} 3)$}

Volume biogas dapat dihitung dengan formula sederhana :

$\mathbf{V}=\pi \mathbf{r}^{2} \times \mathbf{d}$

$\mathrm{V}=$ volume biogas

$\mathrm{r}=$ jari-jari tanki merah muda

$\mathrm{d}=$ jarak dari tutup ke lubang

\subsubsection{Tekanan biogas}

Pengukuran tekanan dengan sensor barometrik BMP180 akan menggunakan formula sebagai berikut :

$$
P=P_{0} \times\left(1-\frac{h}{44330}\right)^{5,255}
$$

$\mathrm{P}=$ tekanan di mana barometer diletakkan

$\mathrm{P}_{0}=$ tekanan atmosfer

$\mathrm{H}=$ ketinggian sensor dari posisi air laut

\subsubsection{Pembuatan bahan Biogas}

Bahan biogas dibuat dengan mencampur sampah organik, kotoran sapi, dan air dengan perbandingan sebagai berikut :

Tabel 1. Tabel percobaan

\begin{tabular}{|c|c|c|}
\hline Perco & Komposisi & Total \\
\hline
\end{tabular}

JURNAL ILMIAH ELEKTRONIKA DAN KOMPUTER, Vol.14, No.1, Juli 2021, pp. 26-34 
p-ISSN: 1907-0012 e-ISSN : 2714-5417

\begin{tabular}{|c|r|r|c|c|}
\hline $\begin{array}{c}\text { baan } \\
\text { ke }\end{array}$ & $\begin{array}{c}\text { Kotoran } \\
\text { Sapi }\end{array}$ & $\begin{array}{c}\text { Sampah } \\
\text { Organik }\end{array}$ & Air & (Kg) \\
\hline 1 & $30 \%$ & $20 \%$ & $50 \%$ & $100 \%$ \\
\hline 2 & $40 \%$ & $30 \%$ & $30 \%$ & $100 \%$ \\
\hline 3 & $50 \%$ & $40 \%$ & $10 \%$ & $100 \%$ \\
\hline
\end{tabular}

\subsubsection{Pembuatan Perangka IoT, Web dan Server}

Perangkat IoT kami desain menggunakan raspberry pi 3 yang digabungkan dengan berbagai modul sensor seperti DHT 12, ultrasonic, raindrop sensor, dan sensor barometer. Perangkat IoT selanjutnya diletakkan di dalam ruang perangkat IoT pada tangki penyimpanan biogas. Pada web monitoring digester portabel terdapat halaman untuk memonitor nomor digester portabel, volume biogas, jarak tangki penampung biogas, tekanan tangki, dan suhu tangki, posisi keran (buka/tutup).

\subsubsection{Laju pembakaran (liter/menit)}

Laju pembakaran merupakan kecepatan bahan bakar habis pada tangki biogas menggunakan kompor tekan sistem injeksi langsung. Laju pembakaran dapat dihitung menggunakan persamaan di bawah ini :

$\alpha=\frac{V}{t}$

$\alpha=$ laju pembakaran (liter/menit)

$\mathrm{V}=$ volume biogas (liter)

$\mathrm{t}=$ waktu sampai bahan bakar habis (menit)

\subsubsection{Laju pembangkit Listrik}

Laju pembangkit listrik digunakan sebagai uji fungsional pada penelitian. Uji ini bertujuan untuk menghitung kecepatan biogas habis pada tangki saat dikonversi menjadi energi listrik dengan menggunakan Yamamax Pro 1200 Rubicon 2 Tak Genset 750 Watt. Laju pembangkit listrik dapat dihitung menggunakan persamaan di bawah ini :

$\beta=\frac{V}{t}$

$\beta=$ laju pembangkit listrik (liter/menit)

$\mathrm{V}=$ volume biogas (liter)

$\mathrm{t}=$ waktu sampai bahan bakar habis (menit)

\section{HASIL DAN PEMBAHASAN}

4.1 Perhitungan volum digester

$\mathrm{V}=\pi \mathrm{r}^{2} \times \mathrm{t}$

$=3,14 \times(45)^{2} \times 65$

$=413,302 \mathrm{~cm}^{3}$

$=413,302$ liter $\approx 414$ liter

\subsection{Banyaknya kotoran sapi dan sampah organic yang dibutuhkan}

Dalam perhitungan untuk menentukan jumlah kotoran sapi dan sampah organik yang dibutuhkan untuk menghasilkan biogas yang akan digunakan:

1. Volum digester $=414$ liter

2. Kotoran Sapi $50 \%$

3. Sampah rumah tangga $40 \%$

4. Air $10 \%$

4.3 Persentasi Total Solid (TS) dan Volatile Solid (VS) Kotoran Sapi Tabel 2. Persentasi Total Solid (TS) dan Volatile Solid (VS) Kotoran Sapi

\begin{tabular}{|l|r|}
\hline$\% \mathrm{TS}=21 \% \times$ P Produksi kotoran Sapi $(\mathrm{kg} /$ hari) & 4,20 \\
\hline$\% \mathrm{VS}=78 \% \times \mathrm{TS}(\mathrm{kg} /$ hari $)$ & 3,28 \\
\hline
\end{tabular}

\subsection{Persentasi Total Solid (TS) dan Volatile Solid (VS) Sampah Dapur}


Tabel 3. Persentasi Total Solid (TS) dan Volatile Solid (VS) Sampah Dapur

\begin{tabular}{|l|r|}
\hline$\% \mathrm{TS}=10 \%$ x Produksi Sampah Dapur (kg/hari) & 1,60 \\
\hline$\% \mathrm{VS}=79 \% \times \mathrm{TS}(\mathrm{kg} /$ hari $)$ & 1,26 \\
\hline
\end{tabular}

4.5 Potensi Volume Biogas (PVB) $\mathrm{m} 3 / \mathrm{hari}$

Tabel 4. Potensi Volume Biogas (PVB) $\mathrm{m} 3 /$ hari

\begin{tabular}{|l|r|}
\hline $\mathrm{PVB}=0.04 * \% \mathrm{TS}$ Kotoran Sapi & 0,17 \\
\hline $\mathrm{PVB}=0.04 * \% \mathrm{TS}$ Sampah Dapur & 0,06 \\
\hline Potensi Volume Biogas Per Hari & 0,23 \\
\hline Potensi Volume Biogas Per Jam & 0,01 \\
\hline
\end{tabular}

4.6 Waktu yang dibutuhkan Gas Kolektor kapasitas 48 L Penuh (Jam) Tabel 5. Waktu yang dibutuhkan Gas Kolektor kapasitas 48 L Penuh (Jam) \begin{tabular}{|l|r|}
\hline $0.048 \mathrm{~m} 3$ / Total PVB m3/hari * 24 Jam/hari & 4,97 \\
\hline
\end{tabular}

4.7 Rata2 Produksi Gas per $\mathrm{m} 3$ per hari (K) dalam Persen (\%)

Tabel 6. Rata2 Produksi Gas per $\mathbf{m} 3$ per hari (K) dalam Persen (\%)

\begin{tabular}{|l|r|}
\hline $\begin{array}{l}\mathrm{K}=\text { Potensi Volume Biogas (PVB) kotoran Sapi/ VS } \\
* 100 \%\end{array}$ & 5,13 \\
\hline $\begin{array}{l}\mathrm{K}=\text { Potensi Volume Biogas (PVB) Sampah Dapur/ VS } \\
* 100 \%\end{array}$ & 5,06 \\
\hline
\end{tabular}

4.8 Volume Gas Metana (VGM) Biogas

Tabel 7. Volume Gas Metana (VGM) Biogas

\begin{tabular}{|l|r|}
\hline VGM $=65.7 \%$ x PVB Kotoran Sapi m3/hari & 0,11 \\
\hline VGM $=65.7 \%$ x PVB Sampah Dapur m3/hari & 0,04 \\
\hline
\end{tabular}

4.9 Energi Listrik yang bisa dihasilkan dari Biogas

Tabel 8. Energi Listrik yang bisa dihasilkan dari Biogas

\begin{tabular}{|l|r|}
\hline $\begin{array}{l}\text { E = VGM Kotoran Sapi x Faktor Konversi } 4.7 \times 1000 \\
(\mathrm{Wh})\end{array}$ & 518,77 \\
\hline $\begin{array}{l}\text { E = VGM Sampah Dapur x Faktor Konversi } 4.7 \times 1000 \\
(\mathrm{Wh})\end{array}$ & 197,63 \\
\hline Total Potensi Energi (Wh) per hari & 716,39 \\
\hline
\end{tabular}

\subsection{Hasil Produksi Biogas}

Hasil Produksi Biogas selama 30 hari

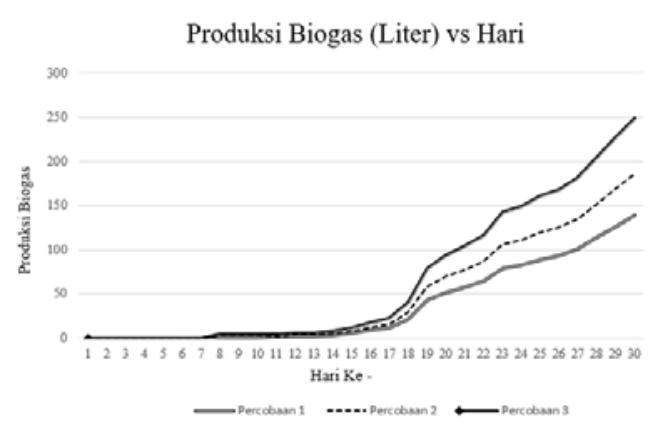

Gambar 3. Hasil Produksi Biogas selama 30 hari

\subsection{Interface sistem monitoring GENBIOT}

JURNAL ILMIAH ELEKTRONIKA DAN KOMPUTER, Vol.14, No.1, Juli 2021, pp. 26-34 

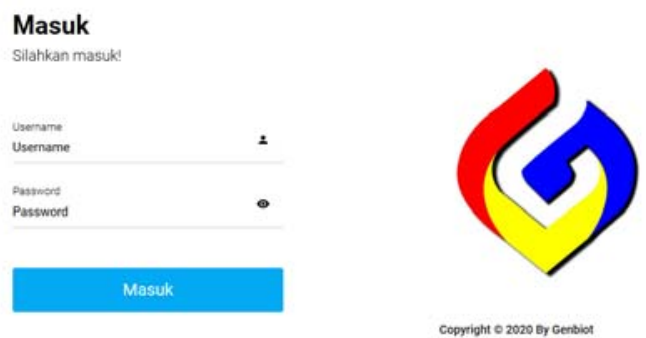

Gambar 4. Halaman login

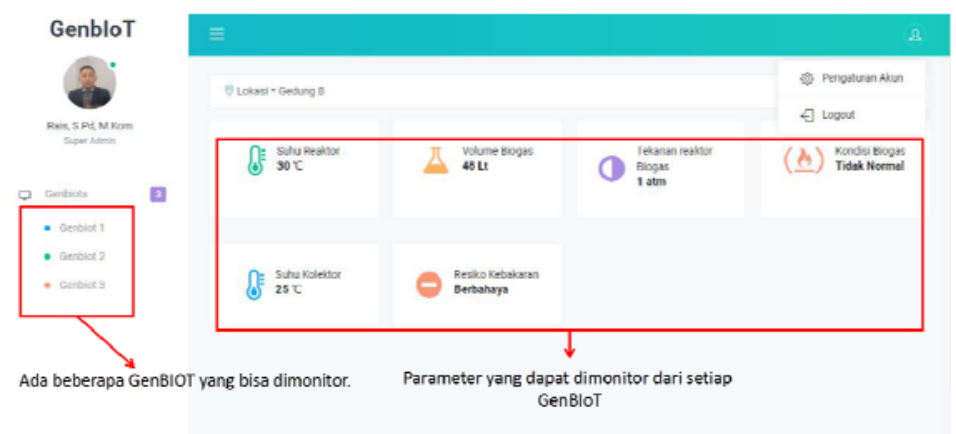

Gambar 5. Halaman monitoring

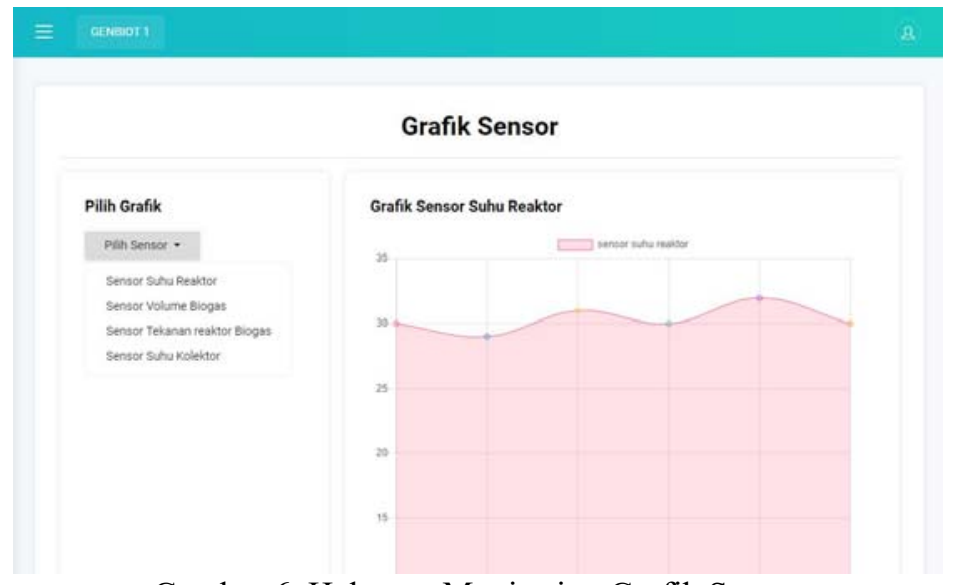

Gambar 6. Halaman Monitoring Grafik Sensor

\section{KESIMPULAN DAN SARAN}

5.1 Kesimpulan

GenBIoT ini memberikan dampak positif bagi masyarakat selain kotoran sapi sampah organik juga dapat dimanfaatkan untuk menghasilkan bio gas sehingga polusi akan sampah semakin berkurang. Dalam produksi biogas kebutuhan komposisi sampah rumah tangga 40\%, 50\% kotoran sapi dan air 10\% dengan perbandingan 4:5:1 akan menghasilkan $40 \mathrm{~kg}$ biogas dengan volum gas metana (VGM) biogas $0,11 \mathrm{~m} 3$ untuk kotoran sapi dan 0,04 m3. Percobaan ketiga menjadi landasan untuk produksi biogas masa mendatang dengan energi yang dihasilkan dari bio gas per hari sebesar 716,39 Wh. Besar tekana pada tabung reaktor serta volume biogas pada digester portable dapat dimonitoring melalui system yang diberinama GenBIoT.

\subsection{Saran}

GenBIoT ini merupakan digester portable yang mudah untuk dipindahkan dan dapat dimonitoring melalui system berbasis web namun GenBIoT ini akan lebih sempurna jika ditambahkan lagi GenBIoTnya minimal 
2 buah agar volume biogas yang dihasilkan semakin besar sehingga laju pembakaran yang dihasilkan lebih lama serta energi yang dihasilkan lebih besar.

\section{DAFTAR PUSTAKA}

[1] N. . Al Bahriyatul Baqiroh, "Timbulan Sampah Nasional Capai 64 juta ton per Tahun,” 2019. https://ekonomi.bisnis.com/read/20190221/99/891611/timbulan-sampah-nasional-capai-64-jutaton-per-tahun (accessed Feb. 21, 2020).

[2] C. Indonesia, "4 Persen Sampah di Indonesia Masih Tak Terkelola," 2018. http://litbang.kemendagri.go.id/website/riset-24-persen-sampah-di-indonesia-masih-tak-terkelola/ (accessed Apr. 25, 1BC).

[3] P. PLN, "Rencana Usaha Penyediaan Tenaga Listrik."

[4] U. Riyadi, G. A. Kristanto, and C. R. Priadi, "Utilization of steel wool as removal media of hydrogen sulfide in biogas," IOP Conf. Ser. Earth Environ. Sci., vol. 105, no. 1, 2018, doi: 10.1088/1755-1315/105/1/012026.

[5] A. Felix, "Pembuatan Biogas Dari Sampah Sayuran," J. Teknol. Kim. dan Ind., vol. 1, no. 1, pp. 103-108, 2012.

[6] M. Marsudi, "Produksi Biogas Dari Limbah Rumah Tangga Sebagai Upaya Mengatasi Krisis Energi Dan Pencemaran Lingkungan,” Turbo J. Progr. Stud. Tek. Mesin, vol. 1, no. 2, pp. 77-85, 2012, doi: $10.24127 /$ trb.v1i2.650.

[7] R. Bangun, R. Biogas, T. Portable, D. Limbah, and K. T. Sapi, "Design of Portable Biogas Reactor Type for Cow Dung Waste," J. Ilm. Rekayasa Pertan. dan Biosist., vol. 5, no. 1, pp. 369-374, 2017, [Online]. Available: guyupmdp@gmail.com. 